\title{
Simple Method for Determining The Bare Soil Resistance to Evaporation
}

\section{蒸発に与える裸地表面抵抗の評価法の提案}

\author{
Ali Abdel-Rahman MOHAMED ${ }^{*}$, Kunio WATANABE** \\ and Ushio KUROKAWA ***
}

\begin{abstract}
A simple method has been developed on the basis of the Watanabe's new technique for measuring evaporation, to calculate both the bulk resistance and the aerodynamic resistance of the soil to vapor diffusion. The aerodynamic resistance was used for isolating the real surface resistance from the bulk resistance. Also it was used for calculating surface, momentum and sensible heat roughness lengths for the bare sand soil. Laboratory tests were carried out on fine and coarse sand under a constant temperature and humidity conditions, to compare the results of steady evaporation, surface resistance, aerodynamic resistance and roughness lengths. It was found that, the steady evaporation from fine sand is much larger than that from coarse sand under the same conditions of relative humidity, temperature, depth of the ground water table, etc. The surface resistance for both fine and coarse sand was modeled as a power function of the top 0 to $0.50 \mathrm{~cm}$ soil moisture. The results indicated that, the surface resistance of the fine sand is much smaller than that of the coarse sand when the two types of sand were put under the same conditions. The two types of sand have almost the same aerodynamic resistance under the same wind conditions. A proposed iterative technique was used to calculate surface, momentum, and sensible heat roughness lengths for the two types of sand. Measurements were done and back analysis technique was used for determining the unsaturated hydraulic properties on the basis of van-Genuchten's model. The Finite Element Method with Galerkin's technique has been used to analyze the moisture movement in the unsaturated zone to get the top soil moisture content at any time during the evaporation process.
\end{abstract}

Key Words: bare soil, surface resistance, aerodynamic resistance, evaporation.

* Doctoral Student, Graduate School of Science and Engineering, Saitama University, Japan.

* $*$ Dr. Eng., Associate Prof., Hydroscience and Geotechnology Laboratory, Faculty of Eng., Saitama University, Japan.

$* * *$ Forestry and Forest Products Research Institute, Japan. 


\section{要 旨}

地表からの蒸発散量の評価は、流出解析や灌溉計画などの水文学的諸問題の解決や表層 地下水の解析を行う上で極めて重要である。蒸発散量の評価法の一つに、地表面抵抗 (Surface resistance) と空気抵抗 (Aerodynamic resistance)を用いて、空気湿度から求める 方法がある。この方法の問題点はこれらの抵抗をいかに推定するかであった。これらの抵 抗值を実験的に求め、性質を定量評価するためには、真の蒸発量を知らねばならない。し かしながら、真の蒸発量を測定することは容易ではない。今回、新たに開発した蒸発散計 測装置を用いて蒸発量を求め、これらの抵抗を評価する方法を研究した。研究は室内実験 により行った。実験では、細砂と粗砂の 2 つの材料を用いて、地表面付近(表面から $0.5 \mathrm{~cm}$ 深まで)の飽和度がそれら抵抗に与える影響を調べた。研究の中で、裸地砂質土の 地表面抵抗と飽和度の関係を実験的に得た。また、空気抵抗を算定し、求められた地表面 抵抗と比較した。その結果、飽和度の高い状態を除いて、地表面抵抗が空気抵抗より大き く、飽和度の小さい状態では、地表面抵抗を用いて裸地蒸発量が概略的に評価しうる可能 性を指摘した。

\section{Introduction}

The water which evaporates at a bare soil surface is transported to the surface through the underlying layers of the soil profile. The exact formulation of this transport is rather complicated (e.g., Philip, 1957; De Vries; 1958; Brutsaert, 1982), since the water transport takes place both in the liquid and vapor phase, involving not only pressure gradients and gravity but often also temperature gradients with a soil heat flux, and salt concentration gradients. In particular two such situations are of interest, namely evaporation in the presence of a water table, and unsteady evaporation from soil profile without water table. In the first case, the water flows from the water table through the soil profile to the soil surface, where it is taken away by evaporation. In the second case, the water which evaporates from the soil surface is supplied by a release from storage in the soil profile.

The dominant process of evaporation from bare soil surfaces is the vapor diffusion through the top layer. This process is not only a function of soil physical parameters such as moisture, vapor pressure and temperature gradients, matric forces, pore diameter, etc. (Philip, 1957; Van Bavel \& Hillel, 1976; van de Griend \& Manfred, 1994), but also a function of air turbulence at the soil-atmosphere interface (Fukuda, 1955; Farrell et al., 1966; Scotter \& Raats, 1969; Ishihara et al., 1992; van de Griend \& Manfred, 1994). Models of the evaporation from both bare soil and vegetated surfaces may be formulated as proportional to the difference in vapor pressure between the evaporating surface and the atmosphere, divided by the sum of the resistance parameters to the movement of the water vapor. These resistance parameters are generally specified as the surface resistance and the aerodynamic resistance. Physically based models for the aerodynamic resistance and the surface (or stomatal) resistance for vegetation have been developed. However, the knowledge on bare surface resistance is not so much. Also unfortunately, field experiments are relatively difficult to control the conditions especially, when comparison between the results measured at different times is needed. An obvious advantage of the laboratory studies is that the experimental conditions can be much better controlled and monitored.

In our experimental study, we compared the 
evaporation from both fine and coarse sand soil in the presence of a water table. Also the bulk resistance, the aerodynamic resistance, the surface resistance, the surface roughness length, the momentum roughness length and the roughness length for the sensible heat flux for the two types of sand were calculated. The concept described in this paper, was used to determine the soil resistance under bare conditions. Actually, the wind conditions inside the box and in the actual field may be not the same. However, most of the measurements and calculations don't mainly depend on the wind conditions. On the other hand, there are some plant's constructions (for example greenhouses) have conditions very near to the box conditions. In future, we need to search this problem and we shall try to simulate the actual field wind conditions in another box type.

\section{Conceptual Basis}

\subsection{Surface resistance}

Mahfouf \& Noilhan (1991) performed a comparative study of various formulations of evaporation from bare soil and concluded that the major difficulty is to establish a physically based relationship between soil evaporation and top soil moisture. The establishment of such a relationship requires independent measurements of the soil surface resistance under various moisture conditions and for different soil types (van de Griend \& Manfred, 1994).

The surface resistance is intended to account for the obstructions to flow from the water vapor source to a point just outside the surface. Shu Fen Sun (1982) has proposed that the surface resistance $\left(r_{\text {surf }}\right)$ may be estimated by

$$
r_{\text {surf }}=C_{1}\left(\frac{\theta_{\text {sat }}}{\theta_{\text {surf }}}\right)^{2.3}+C_{2}
$$

where $C_{1}$ and $C_{2}$ are constants dependent on the soil type, and $\theta_{\text {surf }}$ and $\theta_{\text {sat }}$ are the volumetric soil moisturecontent in the 0 to $0.5 \mathrm{~cm}$ top layer and the saturation value respectively (Camillo \& Gurney, 1986). Camillo \& Gurney (1986) concluded that the surface resistance can be modeled as follows

$$
r_{\text {surf }}=-C_{1}+C_{2}\left(\theta_{\text {sat }}-\theta_{\text {surf }}\right)
$$

where $C_{1}, C_{2}, \gamma_{\text {surf }}, \theta_{\text {surf }}$ and $\theta_{\text {sat }}$ have been previously defined. Kondo et al. (1990) have proposed the following equation

$$
r_{\text {surf }}=C_{1}\left(\theta_{\text {sat }}-\theta_{\text {surf }}\right)^{C_{2}}
$$

van de Griend \& Manfred (1994) found that the relationship between the surface resistance $\left(r_{\text {surf }}\right)$ and the volumetric soil moisture content at the surface $\left(\theta_{\text {surf }}\right)$ is as follows

$$
r_{\text {surf }}=r_{s l} e^{C\left(\theta_{\text {emp }}-\theta_{\text {surf }}\right)} \quad \text { for } \theta_{\text {surf }} \leqq \theta_{\text {emp }}
$$

where $r_{s}$ is the resistance to molecular diffusion across the water surface itself, $\theta_{e m p}$ is an empirical minimum value of the soil moisture content above which the soil is able to deliver vapor at a potential rate, and $C$ is a constant depends on the soil type.

\subsection{Aerodynamic resistance}

Following Thom (1975), van de Griend \& van Boxel (1989) and Kalma \& Jupp (1990) the aerodynamic resistance for sensible heat $\left(r_{a h}\right)$ is given as

$$
\begin{aligned}
& r_{a h}= \\
& \frac{\left\{\ln \left[\left(z 1-d_{o}\right) / z_{o m}\right]-P_{1}\right\}\left\{\ln \left[\left(z 1-d_{o}\right) / z_{o h}\right]-P_{2}\right\}}{k^{2} u}
\end{aligned}
$$

where $u$ is the wind speed at height $z 1$ above the surface, $k$ is the Karman's constant, $P_{1}$ and $P_{2}$ are the stability functions, $d_{o}$ is the (zero-plane) displacement height, $z_{o m}$ and $z_{o h}$ are the roughness lengths for momentum and sensible heat respec- 
tively, $z 1$ is the height above the surface where the meteorological data were measured. The (zeroplane) displacement height $\left(d_{0}\right)$ can be taken zero for bare soil (van de Griend \& Manfred, 1994). The stability functions $P_{1}$ and $P_{2}$ are integral stability functions of $\zeta=\left(z 1-d_{o}\right) / L$ for momentum and sensible heat transfer respectively. $L$ is the Obukhov's length, defined as in Brutsaert (1982), Kalma \& Jupp (1990) and Vogt \& Jaeger (1990) as

$$
L=\frac{-\rho u_{*}^{3}}{\left\{k g\left(\frac{H}{C_{p} T_{a}}\right)+0.61 E\right\}}
$$

where $\rho$ is the air density, $C_{p}$ is the air specific heat at constant pressure, $T_{a}$ is the air temperature, $u_{*}$ is the frictional velocity, $\mathrm{g}$ is the gravitational acceleration constant $\left(980 \mathrm{~cm} / \mathrm{s}^{2}\right), H$ is the sensible heat flux, $E$ is the evaporation rate and $k$ is the Karman's constant. The shear velocity $\left(u_{*}\right)$ can be defined as in Brutsaert (1982) and Camillo \& Gurney (1986) as follows

$$
u_{*}=\frac{u k}{\left\{\ln \left(\frac{z 1-d_{o}}{z_{o m}}\right)-P_{1}\right\}}
$$

where all variables have been previously defined. The sensible heat flux $(H)$ can be defined as

$$
I=\frac{-\rho C_{p}\left(T_{\text {surf }}-T_{a}\right)}{r_{a h}}
$$

where $T_{\text {surf }}$ is the soil surface temperature and all other variables have been previously defined.

Evaluation of the stability functions $P_{1}$ and $P_{2}$ is dependent on whether the surface layer is stable, neutral or unstable. Following Brutsaert (1982), Camillo \& Gurney (1986) and Kalma \& Jupp (1990) the stability functions $P_{1}$ and $P_{2}$ can be modeled as follows

-For a neutral atmosphere, defined by $(\zeta=0)$, the stability functions $P_{1}$ and $P_{2}$ are zero.
-For an unstable atmosphere, defined by $(\zeta<0)$, the following expressions are used

$$
\begin{aligned}
& p_{1}=2 \ln \left(\frac{1+X}{2}\right)+\ln \left(\frac{1+X^{2}}{2}\right) \\
& -2 \tan ^{-1}(X)+\frac{\pi}{2} \\
& p_{2}=2 \ln \left(\frac{1+X^{2}}{2}\right) \\
& X=(1-16 \zeta)^{0.25}
\end{aligned}
$$

-For a stable atmosphere, defined by $(\zeta>0)$, the ratio of $z 1$ to $L$ must be examined

a) If $z 1 / L \leqq 1$, "moderately stable conditions" then

$$
P_{1}=P_{2}=-5 \zeta
$$

b) If $z 1 / L>1$, "extremely stable conditions" then

$$
p_{1}=p_{2}=-5 \ln \left(z 1 / z_{0}\right)
$$

These equations for the stable and unstable cases should be solved iteratively as the relationship between the Obukhov's length and the stability functions is not straight forward. This model will be used later in this paper to calculate the surface roughness length $\left(z_{0}\right)$, the momentum roughness length $\left(z_{o m}\right)$ and the sensible heat roughness length $\left(z_{o h}\right)$ for both coarse and fine sand

\section{Experimental Approach}

\subsection{Evaporation measuring technique}

Figure 1 schematically shows the measuring equipment. Although the dimensions are different, the same technique which was proposed by Watanabe \& Tsutsui (1994) was used to measure the evaporation. The main idea of this technique depends on covering some parts of the ground surface by a box made of transparent sheet, injecting air from one side and extracting this air from the 


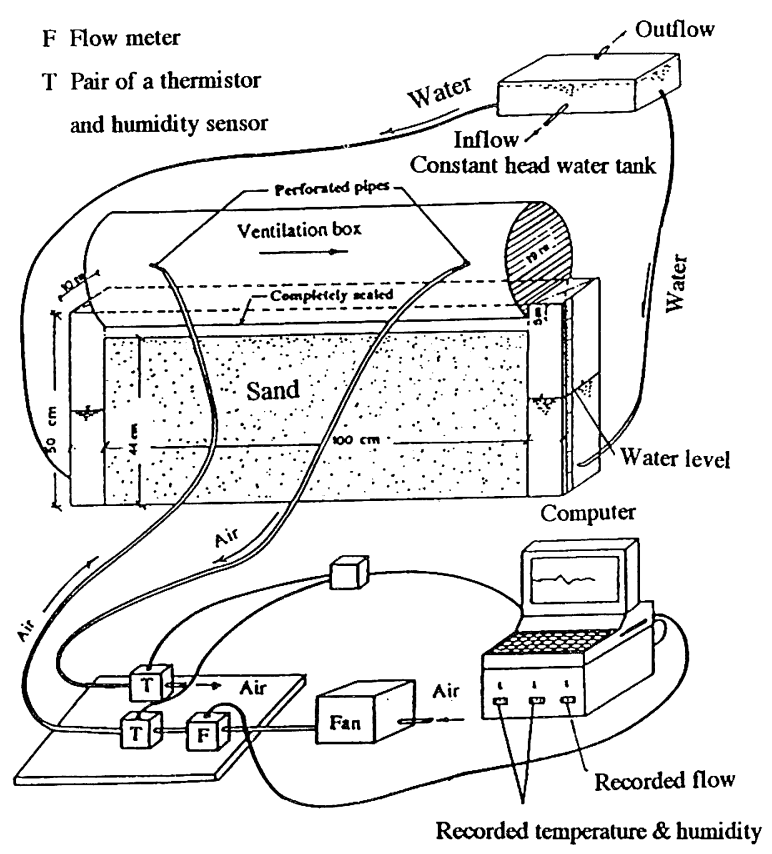

Figure 1. Schematic view of the measuring equipment.

opposite side. The absolute humidity of the extracted air will be larger than that of the injected air when the vapor comes out from the ground surface by evaporation and/or evapotranspiration. The air enters and goes out from the box through two perforated pipes located at the entrance and at the exit of the box to make the flowing air and the evaporated water to be completely mixed (See Fig. 1). During the experiment the relative humidity and temperature of the injected and extracted air are measured. The absolute humidity is calculated from both of relative humidity and temperature of the air as follows

$$
\begin{aligned}
& e_{a}=\frac{e_{a}^{*} h_{r}}{100} \\
& \beta=\frac{0.622 e_{a}}{R_{d} T_{a}}
\end{aligned}
$$

where $e_{a}$ is the water vapor pressure, $e_{a}{ }^{*}$ is the saturation vapor pressure at the air temperature, $h_{r}$ is the relative humidity, $\beta$ is the absolute humidity, $R_{d}$ is the specific gas constant for dry air, $T_{a}$ is the air temperature, and the constant 0.622 is the ratio of the molecular weights of water and dry air. By measuring the air flow rate and calculating the values of the absolute humidity of the injected and extracted air, the evaporation rate $(E)$ can be simply calculated from the following basic equation as

$$
E=\frac{Q\left(\beta_{\text {out }}-\beta_{\text {in }}\right)}{A}
$$

where $\beta_{\text {out }}$ and $\beta_{\text {in }}$ are the absolute humidity of the extracted and injected air respectively, $Q$ is the volumetric flow rate of the air that is injected and extracted from the box and $A$ is the covered area by the box.

Kurokuwa et al. (1995) have checked the accuracy of this equipment for determining evaporation and evapotranspiration.

\subsection{Laboratory tests}

Laboratory tests were carried out under constant relative humidity (55\%) and air temperature during all experiments. The air temperature was slightly increased during the time of the experiment due to the heat from the motor conducted by the axis to the propeller and the friction heat created as a result of the fast rotating propeller. The soil materials used were clean and pure sandy soil (fine and coarse). The experiments were conducted on sandy soil inside a perspex box with interior dimensions of $100 \mathrm{~cm}$ length, $10 \mathrm{~cm}$ width and $50 \mathrm{~cm}$ height (See Fig. 1). The depth of the soil inside the box was $44 \mathrm{~cm}$. The ends of the box were connected with two reservoirs each 10 $\mathrm{cm}$ width, $10 \mathrm{~cm}$ length and has the same height of the box. The two reservoirs were separated from the soil column, by two perforated perspex plates and two steel meshes. The two reservoirs were connected with a constant head water tank, to change the ground water table in the soil box. To keep close contact between the perspex side plates and the soil, the inside surface of the side plates was made rough by gluing small pieces of 
sand on the surface. The sides of the box were thermally isolated, to prevent the lateral heat transfer to or from the soil to the surrounding air. This box was covered by a wind tunnel made of a transparent pipe. The lower part of the pipe was cut off so that the vapor could freely enter into the tunnel from its base. The connection between the soil box and the wind tunnel was completely sealed to prevent any air leakage during the experiment. Air was supplied by using an electric blower at a constant average velocity of 10.15 $\mathrm{cm} / \mathrm{s}$. The air flow rate was measured by using a hot wire flow meter. The extracted air from the box was driven outside the room, to keep constant humidity and temperature in the room. During the experiments the values of the relative humidity and temperature of the injected and extracted air, were measured by a couple of thermistor and humidity sensors. All data were sent directly to a computer, to calculate the evaporation and to store all data. The temperature of the soil was measured at six points regularly distributed over the area, at a depth 0 to $0.5 \mathrm{~cm}$ under the surface. The arithmetic mean of these values was considered as the soil surface temperature.

\section{Results and Discussions}

\subsection{Comparison between the steady eva- poration from coarse and fine sand}

Laboratory tests were carried out on fine sand (Toyoura standard sand) and coarse sand to compare the evaporation under the same conditions. Table 1 shows the measured properties of the two types of sand.

The evaporation measurements were per- formed under a constant controlled temperature and relative humidity. The soil surface temperature was nearly stable during the time of each experiment. Figure 2 shows an example of the measured soil surface temperature. It is clear from this figure that the soil surface temperature is higher in the case of coarse sand than that in the case of fine sand. Thus, may be due to that the evaporation rate and accordingly the latent heat flux from the coarse sand are small compared with those from the fine sand under the same conditions. Also it is obvious that the soil surface temperature does not change significantly with time.

To change the volumetric water content at the top of the sand layer, the ground water level in the soil box was changed several times by using the constant head tank, and the evaporation rate was measured each time. We assumed that the steady-state of evaporation was reached when the fluctuation in the measured evaporation rate became negligible. The transient change of the eva-

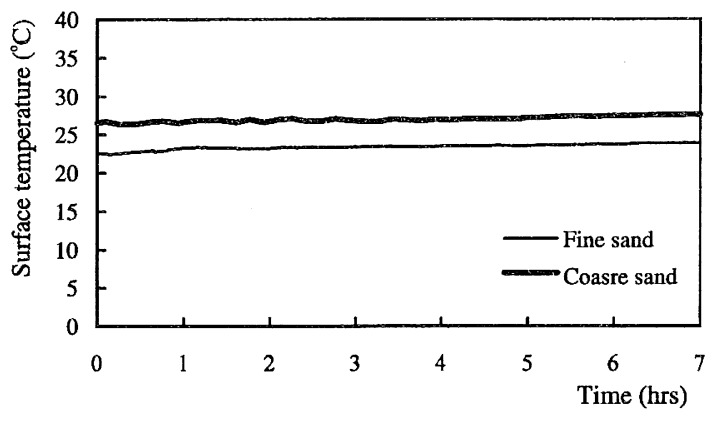

Figure 2. Transient change of the soil surface temperature for both coarse and fine sand (water table was set at $42 \mathrm{~cm}$ depth).

Table 1. Measured properties of the fine and coarse sand.

\begin{tabular}{|l|c|c|c|}
\hline Case & $\begin{array}{c}\text { Mean diameter of the } \\
\text { particle }(\mathrm{mm})\end{array}$ & Porosity (\%) & $\begin{array}{c}\text { Saturated hydraulic } \\
\text { conductivity (cm/s) }\end{array}$ \\
\hline Fine sand & 0.19 & 44.5 & 0.02 \\
\hline Coarse sand & 1.34 & 39.6 & 0.47 \\
\hline
\end{tabular}


poration rate with time for one run as example for the two types of sand is shown in Fig. 3. The ground water table was set at $42 \mathrm{~cm}$ depth under the soil surface. From this figure it is clear that the evaporation rate from the two types of sand starts highly at the beginning of the experiment and decreases rapidly with time until a constant steady value after a period less than 3.5 hours. This behavior means that the moisture inside the sand pores at the beginning of the experiment is higher than that under the case of steady evaporation. This excess of moisture is firstly taken out by evaporation to reach to the steady-state of evaporation. Also it is quite obvious that the evaporation rate from fine sand is higher than that from coarse sand because, the volumetric water content at the thin top layer is greater in the case of fine sand than that in the case of coarse sand under the similar conditions.

To exhibit the effect of the depth of the ground water table on the steady evaporation from both fine and coarse sand, the results were plotted as shown in Fig. 4. From this figure it is observed that at the same depth of the ground water table; the steady evaporation from the fine sand is much larger than that from the coarse sand depending on the value of the volumetric water content at the thin top layer, as discussed

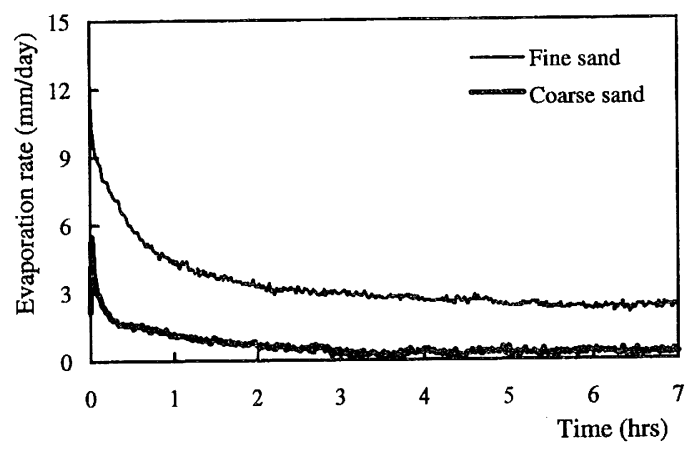

Figure 3. Transient change of the evaporation rate from both coarse and fine sand (water table was set at $42 \mathrm{~cm}$ depth). above. However, when the depth of the ground water table is $2.0 \mathrm{~cm}$ the difference becomes small because, the volumetric water content at the thin top layer is almost near to its saturation value for both the two types of sand. Also it is clearly shown that the steady evaporation from both fine and coarse sand is inversely proportional with the depth of the ground water table. This result is due to the decrease in the volumetric water content at the top of the sand layer when the water level becomes deeper. This decrease in the volumetric water content leads to increase the soil surface resistance and accordingly the evaporation rate decreases. One experiment was done when the ground water table was set at the soil surface and the surface temperature was $25 C^{\circ}$. It was found that the evaporation rate from water surface is much larger than that from the sand surface under the similar conditions (See Fig. 4).

\subsection{Analysis of ground water flow in the un- saturated sand soil}

The soil water transfer in the unsaturated zone can be calculated by solving the classical Richards equation defined as

$$
C(S) \frac{\partial h}{\partial t}=\frac{\partial}{\partial z}\left\{k_{0} r(S) \frac{\partial h}{\partial z}\right\}+q
$$

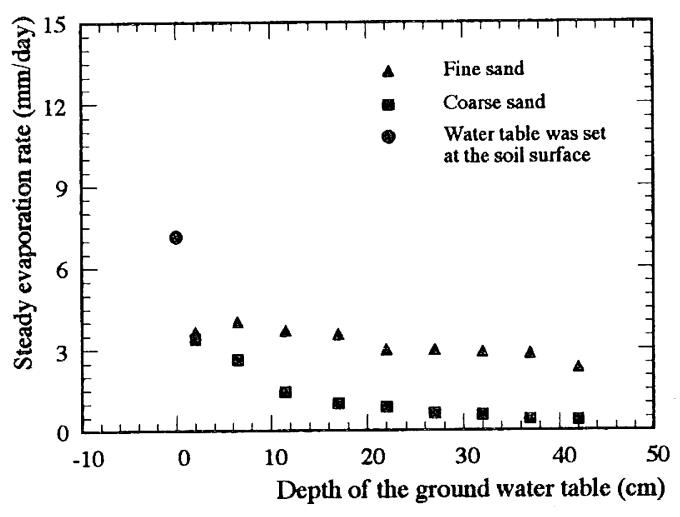

Figure 4. Comparison between the steady evaporation rate from both coarse and fine sand at the different depths of the ground water table. 


$$
h=z+\psi
$$

where $S$ is the saturation, $C(S)$ is the specific water capacity, $k_{o}$ is the saturated hydraulic conductivity, $r(S)$ is the relative hydraulic conductivity, $\mathrm{q}$ is the sink and source term, $h$ is the total head, $t$ is the time, $z$ is the height from a reference level and $\psi$ is the capillary pressure head. Equation (10) can be solved numerically if the boundary and initial conditions of the flow and the properties of the soil are defined. Both the specific water capacity $C(S)$ and the relative hydraulic conductivity $r(S)$ may be defined as a function of the capillary pressure head $(\psi)$ using the vanGenuchten's model (1980) as follows

$$
\begin{aligned}
& S_{e}=\frac{S-S_{\min }}{S_{\max }-S_{\min }} \quad\left(0 \leqq S_{e} \leqq 1\right) \\
& S_{e}=\left\{1+\alpha|\psi|{ }^{n}\right\}^{-m} \quad(\alpha>0) \\
& n=\frac{1}{1-m} \quad(0<m<1, n>1) \\
& r(S)=S_{e}^{1 / 2}\left\{1-\left(1-S_{e}^{1 / m}\right)^{m}\right\}^{2} \\
& C(S)=\alpha(n-1)\left(S_{\max }-S_{\min }\right) S_{e}^{1 / m}\left(1-S_{e}^{1 / m}\right)^{m}(12 \mathrm{e})
\end{aligned}
$$

where $S_{\max }$ and $S_{\min }$ are the maximum and the minimum saturation in an actual unsaturated condition respectively, $\alpha$ and $\mathrm{m}$ and are constants. All of these parameters depend on the soil type. Watanabe et al. (1995) and Abozeid et al. (1996) used field and laboratory measurements and a back analysis technique for estimating the hydraulic properties of unsaturated soil using vanGenuchten's model. By the same manner, the parameters included in the van-Genuchten's model were calculated by the laboratory tests for the two types of sand. The soil was put inside the box under defined boundary conditions (the measured evaporation flux from the surface as the top boundary condition, no-lateral flow was taken and a constant pressure head $\psi=0$ was taken at the position of the ground water table as the bottom boundary) as shown in Fig. 1. This experiment was carried out for a long time under these conditions and at the end of the experiment the vertical saturation ratio distribution was measured. This final saturation ratio distribution and the measured top flux were used in the back analysis to calculate the unsaturated hydraulic properties under the previous boundary conditions. Table 2 shows the calculated parameters of the vanGenuchten's model for the two types of sand.

To check the accuracy of the back analysis calculations, one dimensional unsaturated flow was formed in a soil column of coarse sand with the boundary conditions shown in Fig. 5. The constant pressure condition $(\psi=0)$ was given at the position of the ground water table as the bottom boundary as shown in the figure. Both the side wall and the top of the specimen were completely sealed to avoid the evaporation. The Finite Element Method with Galerkin's technique has been used to solve Eq. (10) under these boundary conditions. The calculated van-Genuchten's parameters were employed during the calculations. The final saturation ratio distribution after one week was calculated from the numerical solution of the differential equation and was measured by taking samples through the height of the specimen. Figure 6 illustrates a comparison between the measured and the calculated saturation ratio dis-

Table 2. Calculated parameters of the van-Genuchten's model for both fine and coarse sand.

\begin{tabular}{|l|c|c|c|c|}
\hline Case & $S_{\min }$ & $S_{\max }$ & $\alpha\left(\mathrm{cm}^{-1}\right)$ & $m$ \\
\hline Fine sand & 0.01 & 0.995 & 0.02642 & 0.89654 \\
\hline Coarse sand & 0.05 & 0.930 & 0.21723 & 0.60069 \\
\hline
\end{tabular}

$S_{m i n}, S_{m a x}$ are the minimum and maximum saturation respectively, $\alpha$ and $m$ are constants. 


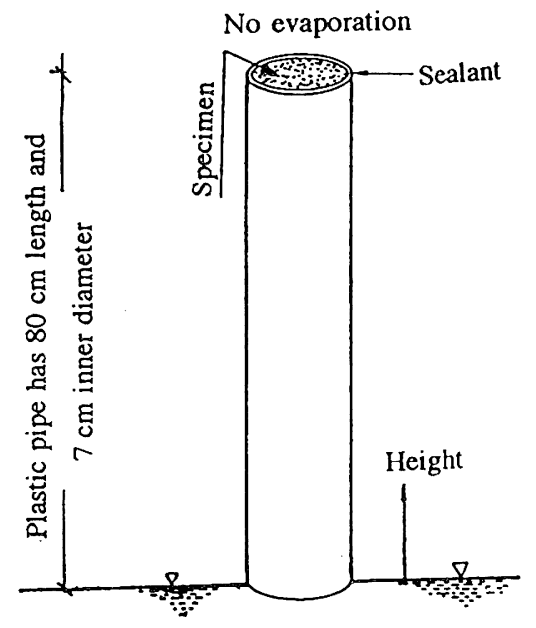

Figure 5. Boundary conditions of the sand specimen.

tribution through the height of the coarse sand specimen. From this figure it is clear that the agreement between the measured and the calculated curves is excellent. Therefore, we can say that the back analysis is highly practical and possible to use to calculate the unsaturated hydraulic properties.

To evaluate the required time to reach to the steady-state of evaporation, the vertical volumetric water content distribution was calculated using the Finite Element Method at different times for the case of the greatest depth of the ground water table in the experiments $(42 \mathrm{~cm})$, to get the most critical conditions. The flux condition at the top surface was taken according to the measured evaporation rate shown in Fig. 3, no-lateral flow was assumed, and a constant pressure head $(\phi=0)$ was given at the position of the ground water table as the bottom boundary. It was found that the vertical moisture distribution of the sandy soil is slightly affected and only within the upper few centimeters by the given evaporation rate. This phenomena is not surprising, because the hydraulic conductivity of the used sand is high enough to supply that small surface flux. After a short time of evaporation (less than 3.5 hours) the influence nearly vanishes as shown in Figs. 7

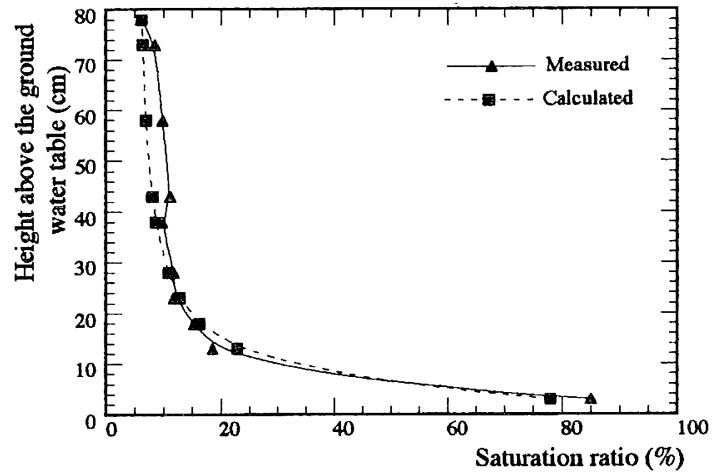

Figure 6. Comparison between the measured and the calculated vertical saturation ratio distribution for the coarse sand.

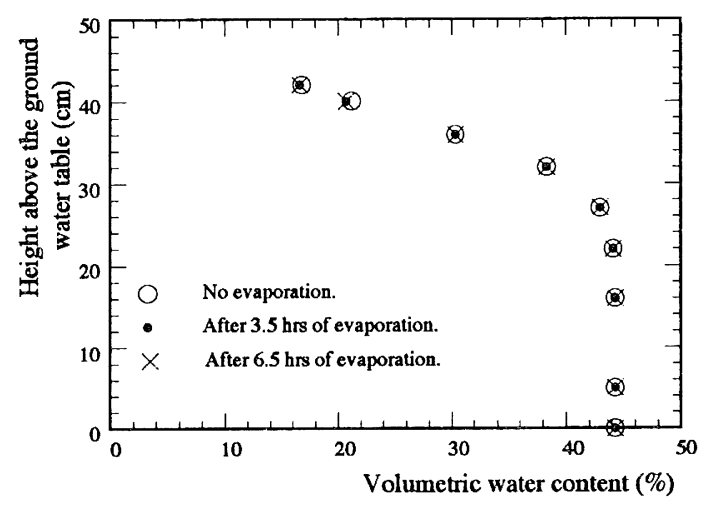

Figure 7. Effect of the evaporation on the vertical volumetric water content distribution of the fine sand.

and 8 for the fine and coarse sand respectively. It can be concluded that the time 7.0 hours for the experiment is quite sufficient to reach to the steady-state of evaporation as assured from Fig. 3.

\subsection{Derivation of the total resistance}

The total resistance parameter is necessary in the latent heat flux term of the soil surface energy balance equation, if the evaporation is not to be overestimated. Such overestimation would lead to gross errors in long-term evaporation estimates and large errors in the day time Bowen ratio. The latent heat flux from the surface into the moving air can be expressed as 


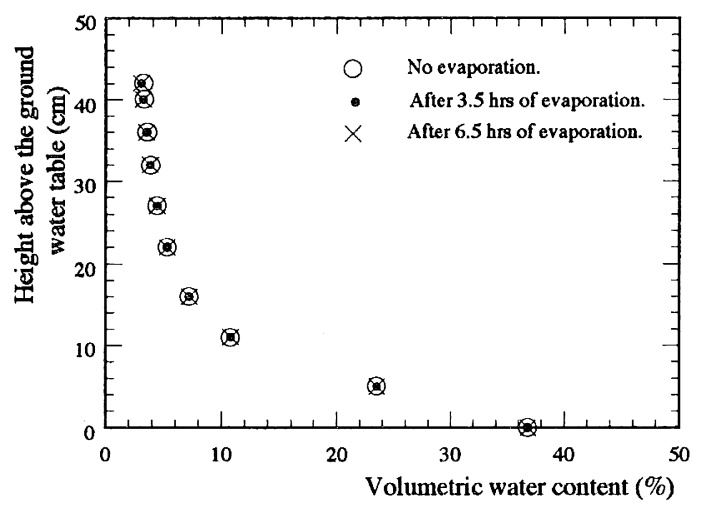

Figure 8. Effect of the evaporation on the vertical volumetric water content distribution of the coarse sand.

$$
L_{e} E=\frac{-\rho C_{p}}{\gamma} \frac{\left(e_{\text {surf }}-e_{a}\right)}{\left(r_{a v}+r_{s u r f}\right)}
$$

where $L_{e}$ is the latent heat of vaporization, $E$ is the evaporation rate, $e_{a}$ is the water vapor pressure of the air at a reference level and $e_{\text {surf }}$ is that at the surface, $\rho$ is the air density, $C_{p}$ is the specific heat of the air at constant pressure, $\gamma$ is the psychrometric constant, $r_{a v}$ is the aerodynamic resistance for vapor flux and $r_{\text {surf }}$ is the surface resistance. For soils, $e_{\text {surf }}$ depends on the matric potential $(\psi)$ and it was described by Philip (1957) as follows

$$
e_{\text {surf }}=e_{\text {surf }}^{*} \exp \left(\frac{g \psi}{R T}\right)
$$

where $e_{\text {surf }}$ is the vapor pressure at the surface, $e^{*}{ }_{\text {surf }}$ is the saturation vapor pressure of the liquid phase at the surface temperature, $R$ is the gas constant for water vapor and $T$ is the Kelvin temperature of the liquid phase. Within the suction range normally encountered under the most conditions, the relative humidity $\left(\frac{e_{\text {surf }}}{e^{*} \text { surf }}\right)$ in the soil gas phase stays very close to $100 \%$, therefore our calculations were under the assumption of saturation vapor pressure at the surface temperature. The psychrometric constant as in Brutsaert (1982) is

$$
\gamma=\frac{C_{p} P}{0.622 L_{e}}
$$

where $P$ is the total pressure in the air. A com bination of Eqs. (13) and (15) leads to

$$
r_{\text {surf }}+r_{a v}=\frac{-0.622\left(e_{\text {surf }}-e_{a}\right) \rho}{P E}
$$

or

$$
r_{t o t}=\frac{-0.622\left(e_{\text {surf }}-e_{a}\right) \rho}{P E}
$$

where $r_{l o t}$ is the total resistance to evaporation. All the terms of the right hand side of Eq. (16), can be measured or calculated to determine the total resistance $r_{t o t}\left(=r_{\text {surf }}+r_{a v}\right)$. Figure 9 shows a typical example of the calculated total resistance versus time. From this figure it is obvious that the total resistance of the coarse sand is much larger than that of the fine sand under the same conditions. The reason for this big difference is due to the higher surface resistance in the case of coarse sand than that in the case of fine sand as it will be explained later. On the other hand, the aerodynamic resistance is almost the same as it will be discussed. Also, the fluctuation in the estimated total resistance is larger in the case of coarse sand than that of fine sand because of the low value of the measured evaporation with a

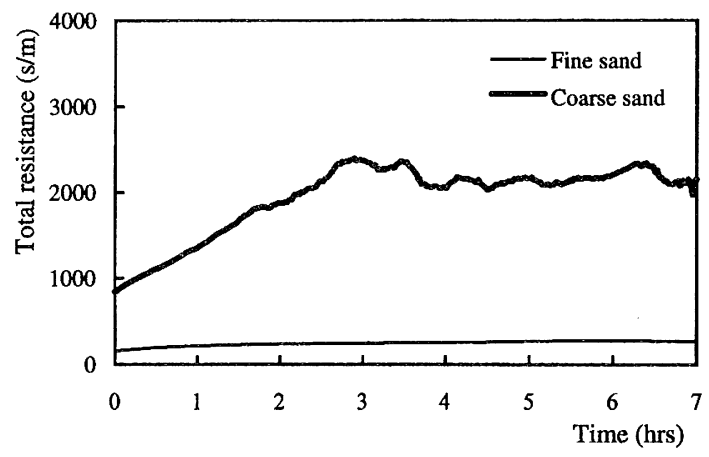

Figure 9. Transient change of the total resistance for both coarse and fine sand (water table was set at $42 \mathrm{~cm}$ depth). 
negative power as shown by Eq. (16). For this reason, any small variance in the measured evaporation from the coarse sand leads to a considerable fluctuation in the total resistance. The ground water table was changed several times and the total resistance was calculated each time for the two types of sand.

\subsection{Derivation of the aerodynamic resistance}

Assuming that the aerodynamic resistance for water vapor $\left(r_{a v}\right)$ mentioned in Eq. (13) and for sensible heat $\left(r_{a l}\right)$ mentioned in Eqs. (5a) and (5d) to be the same. The sensible heat flux from the soil $(H)$ as described by Eq. (5d) was also assumed to be taken by the moving air inside the box, neglecting all other heat sources or sinks. According to the last assumption the heat continuity equation of the used equipment can be given as

$$
H=\frac{-Q \rho C_{p}\left(T_{a(i n)}-T_{a(o u t)}\right)}{A}
$$

where $Q$ is the volumetric flow rate of the air that is injected and extracted from the box, $T_{a(i n)}$ and $T_{a(o u l)}$ are the temperature of the injected and extracted air respectively and $A$ is the bare soil area under the box. The derivation of $r_{a h}$ can be taken from Eqs. (5d) and (17) as follows

$$
r_{a h}=\frac{A\left(T_{\text {surf }}-T_{a}\right)}{Q\left(T_{a(i n)}-T_{a(o u t)}\right)}
$$

According to Eq. (18), the transient change in the calculated aerodynamic resistance with time for one run as example is shown in Fig. 10. It is clear from this figure that the aerodynamic resistance for both fine and coarse sand under the same conditions is nearly the same. The brief explanation of the reason of the same aerodynamic resistance for the two types of sand is that the aerodynamic resistance models the role of the atmospheric stability in reducing the vapor flow (Camillo \& Gurney, 1986) and the conditions inside the box is almost the same for all experiments. Figure 11

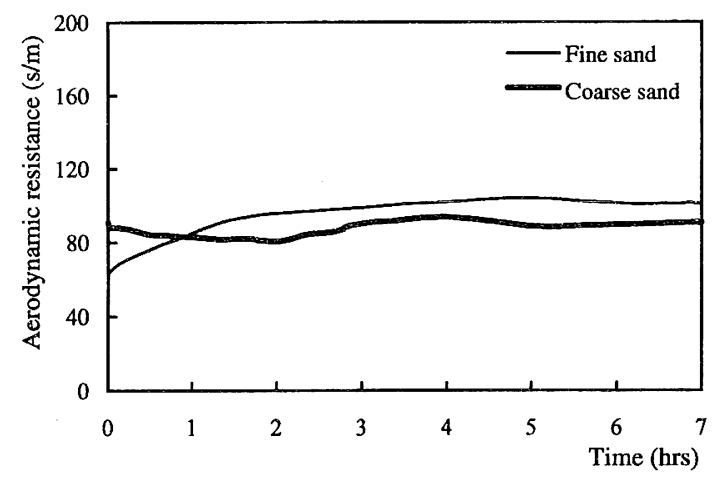

Figure 10. Transient change of the aerodynamic resistance for both coarse and fine sand (water table was set at $42 \mathrm{~cm}$ depth).

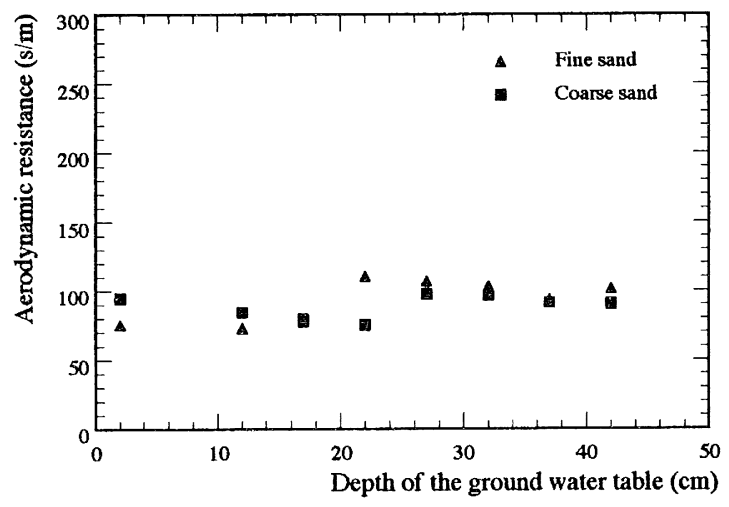

Figure 11. Values of the calculated aerodynamic resistance for both fine and coarse sand versus the depth of the ground water table.

shows a comparison between the calculated aerodynamic resistance for fine and coarse sand under steady evaporation, at the different depths of the ground water table used in the experiments. This figure shows a relatively random and small variation in the aerodynamic resistance with an average value of $93 \mathrm{~s} / \mathrm{m}$ for fine sand and $89 \mathrm{~s} / \mathrm{m}$ for coarse sand. These small variations are resulted from the small changes in the laboratory surrounding conditions and accuracy of the different apparatus used for measurements from one experiment to another. Also, it can be concluded 
that the aerodynamic resistance is independent of the surface moisture conditions.

\subsection{Derivation of the roughness lengths}

Many studies have been conducted to relate the surface roughness length $\left(z_{0}\right)$ with measurable characteristics of the surface. Paeschke (1937) was probably the first to consider this parameter for crop-covered surfaces. In reality, the matter is not as simple as suggested by Paeschke (Brutsaert, 1982). More detailed analysis has shown that the ratio of the mean height of the roughness obstacles to the surface roughness length is, in fact, a fairly complicated function of other surface characteristics as well. Several formulations have been derived for bluff obstacles (e.g., Lettau, 1969; Wooding et al., 1973; Brutsaert, 1982). Unfortunately, the accuracy of these formulations is still quite low.

The momentum roughness length $\left(z_{o m}\right)$ is an important parameter, not only for the wind profile, but it is also essential in the calculation of the water vapor roughness length $\left(z_{o v}\right)$, the roughness length for sensible heat $\left(z_{o h}\right)$ and the roughness parameters for other scalars. The surface roughness $\left(z_{0}\right)$, the momentum roughness $\left(z_{o m}\right)$ and the sensible heat roughness $\left(z_{o h}\right)$ were calculated here by using a proposed iterative technique. This iterative technique was used to solve the group of Eqs. (5a) through (6e) after adding some relations to define the parameters $z_{o m}$ and $z_{o l}$. These two parameters can be defined according to the nature of the surface. The surface can be considered to be hydrodynamically smooth or rough according to the value of the roughness Reynolds number $\left(z_{o+}\right)$ defined as

$$
z_{o+}=\frac{u_{*} z_{0}}{v}
$$

where $v$ is the kinematic viscosity and all other variables have been previously defined. Following Brutsaert (1982) the parameters $z_{o m}$ and $z_{\text {oh }}$ can be defined as follows
-For a smooth surface, that is when $z_{0+}<0.13$, the flow is independent of the nature of the surface and the effect of viscosity must be considered

$$
\begin{aligned}
& z_{o m}=0.135 v / u * \\
& z_{o h}=0.395 v / u *
\end{aligned}
$$

-For a rough surface, that is when $z_{0+}>2.0$, the flow depends on the nature of the surface

$$
\begin{aligned}
& z_{o m}=z_{o} \\
& z_{o h}=7.4 \exp \left(-2.46 z_{o+}^{0.25}\right) z_{o}
\end{aligned}
$$

The following iterative technique was used to solve the group of Eqs. (5a) through (6e) with Eqs. (19) through (23). The case of unstable atmosphere and hydrodynamically rough surface was iterated as follows

a) An appropriate value for $z_{0}$ was assumed;

b) According to this value of $z_{0}$, the value of $u_{*}$ was estimated iteratively from Eqs. (5b), (5c), (5d), (6a), (6b), (6c) and (22);

c) the values of $z_{o+}, z_{o m}, z_{o h}$ and $r_{a h}$ were calculated from Eqs. (19), (22), (23) and (5a), respectively;

d) This calculated value of $r_{a h}$ was compared with that one obtained from the experiment; and

e) If the difference between the two values became smaller than $0.05 \mathrm{~s} / \mathrm{cm}$ the iteration was stopped. Otherwise, the assumed value of $z_{0}$ was changed and the processes b) through d) were repeated.

During the calculations the height $z 1$ was taken as $9.0 \mathrm{~cm}$; equal to the height of the center of gravity of the cross sectional area of the flowing air above the sand surface. The velocity $(u)$ at the height $(z 1)$ was taken as 0.35 of the mean velocity of the flowing air over the whole section of the ventilation box to give an aerodynamic re- 
sistance similar to that one obtained from experiments. Figure 12 shows the calculated values of the roughness Reynolds number for both fine and coarse sand at the different depths of the ground water table. From the values of the roughness Reynolds number for both fine and coarse sand (as shown in Fig. 12) it is clear that the sand surface is hydrodynamically rough. This result is confirmed by Brutsaert (1982), who mentioned that the earth's surface especially its land portion is usually rough.

The calculated surface, momentum and sensible heat roughness lengths for the two types of sand were plotted against the different depths of the ground water table as shown in Fig. 13. From this figure it is obvious that the momentum roughness length $\left(z_{o m}\right)$ for the two types of sand is equal to the surface roughnesslength $\left(z_{0}\right)$. On the other hand, the sensible heat roughness length $\left(z_{o h}\right)$ for the two types of sand is considerable smaller than the surface roughness length $\left(z_{0}\right)$. This is only in the case of the hydrodynamically rough surface as mentioned by Brutsaert (1982). Figs. 12 and 13 illustrate that the roughness Reynolds number, the surface roughness length, the momentum roughness length and the sensible heat roughness length are independent of the surface moisture conditions. The mean values of the calculated roughness lengths at different depths of the ground water table for both fine and coarse sand are given in Table 3. From this table it can be seen that the mean values of the roughness parameters for the two types of sand is almost the same. Actually the small differences in the mean values between the two types of sand may be resulted from the difference in the nature of the surface, its geometry, the size and the arrangement of the roughness.

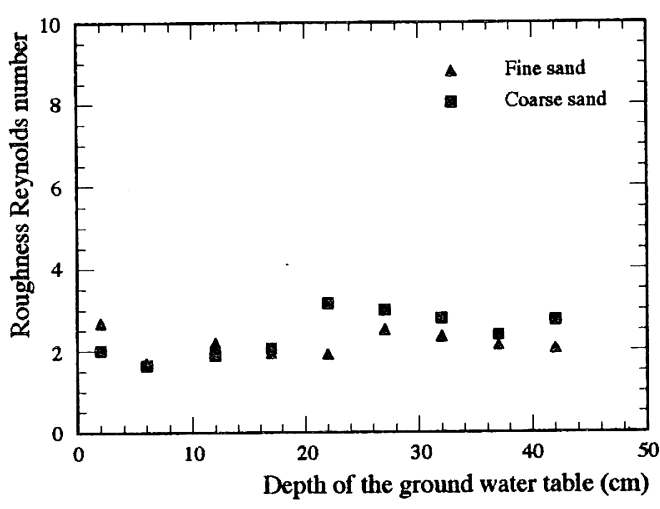

Figure 12. Values of the calculated roughness Reynolds number for both fine and coarse sand versus the depth of the ground water table.

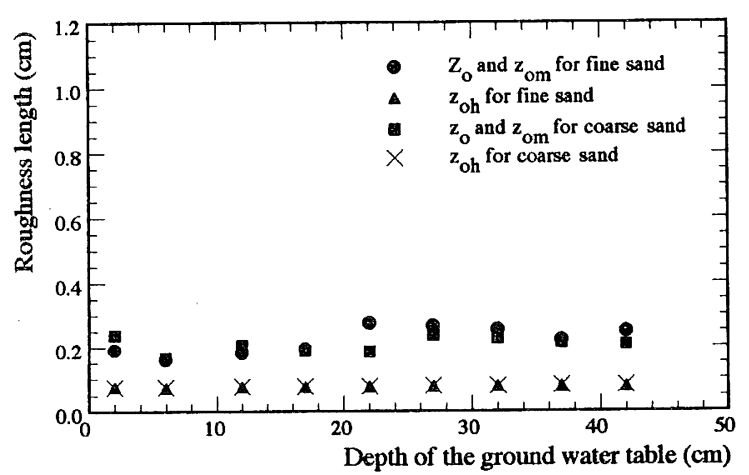

Figure 13. Calculated roughness lengths of surface $\left(z_{o}\right)$, for momentum $\left(z_{o m}\right)$ and for sensible heat $\left(z_{o h}\right)$ for both fine and coarse sand versus the depth of the ground water table.

Table 3. Mean values of the roughness lengths for both fine and coarse sand.

\begin{tabular}{|l|c|c|c|}
\hline Casc & $\begin{array}{c}\text { Surface roughness } \\
\text { length }(\mathrm{cm})\end{array}$ & $\begin{array}{c}\text { Momentum roughness } \\
\text { length }(\mathrm{cm})\end{array}$ & $\begin{array}{c}\text { Sensible heat roughness } \\
\text { length }(\mathrm{cm})\end{array}$ \\
\hline Fine sand & 0.222 & 0.222 & 0.077 \\
\hline Coarse sand & 0.208 & 0.208 & 0.078 \\
\hline
\end{tabular}




\subsection{Derivation of the surface resistance}

There are some suggestions that the surface resistance parameter is related to the soil surface moisture in a linear fashion, which should be investigated with a large data sets. It may then be possible to suggest a function to allow the estimation of this surface resistance parameter from sur face soil moisture data and thus allows an improvement in the accuracy of evaporation estimates. Since, top soil moisture can be monitored by passive microwave remote sensing (Schmugge et al., 1986; van de Griend \& Manfred, 1994) the surface resistance formulation can be used in combination with repetitive soil moisture and surface temperature observation from space. To calculate the values of the surface resistance from these results, the aerodynamic resistance was subtracted from the total resistance. Figure 14 shows a typical example of the calculated surface resistance versus time for both fine and coarse sand. Obviously, from this figure the surface resistance is much larger in the case of coarse sand than that in the case of fine sand. The reason for this big difference is that the volumetric water content in the top thin layer of coarse sand is smaller than that in the case of fine sand under the same condition of depth of the ground water table as shown in Figs. 7 and 8.

To investigate the relation between the surface resistance and the saturation ratio at the top of the sand layer, the saturation ratio was changed several times at the top of the layers of the fine and coarse sand by changing the ground water table using the constant head tank. The Finite Element Method was used to calculate the saturation ratio at the top of the sand layer. For calculation the unsaturated hydraulic properties

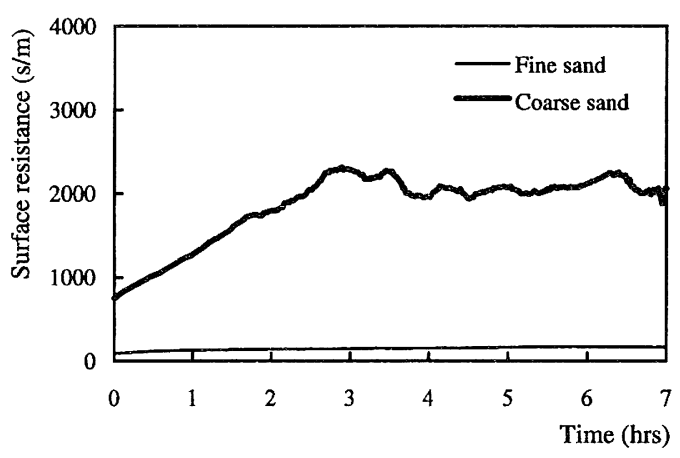

Figure 14. Transient change of the soil surface resistance for both coarse and fine sand (water table was set at $42 \mathrm{~cm}$ depth).

were used in the analysis of the Finite Element Method. The measured evaporation rate at each depth of the ground water table was input as the boundary flux condition at the top surface. Also, no-lateral flow was considered and the constant pressure condition $(\psi=0)$ was given at the location of the ground water table as the bottom boundary condition. In Figs. 15 and 16, all derived surface resistance $\left(r_{\text {sur }}\right)$ in $\mathrm{s} / \mathrm{m}$ were plotted against the calculated saturation ratio $\left(S_{\text {surf }}\right)$ at the top 0 to $0.50 \mathrm{~cm}$ for both fine and coarse sand respectively. It is clear that the surface resistance is small at saturation but increasing in highly nonlinear way when the soil becomes dry. The relationship is typically of power form as deduced by Shu Fen Sun (1982) and Kondo et al. (1990). This power relation can be expressed as follows

$$
r_{\text {surf }}=C_{1}\left(S_{\text {surf }}\right)^{C 2}
$$

where $C_{1}$ and $C_{2}$ are parameters depend on the soil type. The obtained parameters for both fine and coarse sand are as shown in Table 4. It is

Table 4. Values of the parameters $C_{1}$ and $C_{2}$ for both fine and coarse sand.

\begin{tabular}{|l|c|c|}
\hline Parameter & $C_{1}$ & $C_{2}$ \\
\hline Fine sand & 1684.81 & -0.601 \\
\hline Coarse sand & 15667.96 & -1.139 \\
\hline
\end{tabular}


clear from Figs. 15 and 16 that the fitted power curves for the two types of sand agree well with the measured points. However, the agreement is more better in the case of coarse sand than that in the case of fine sand. The reason may be comes from the approximation of the vapor pressure at the surface to the saturated value. This approximation may produce a big error in the case of fine sand than that in the case of coarse sand because, the volume of the soil pores directly adjacent to the soil surface is smaller in the case of fine sand than that in the case of coarse sand. Another probable reason is that, as the top soil dries out, the phase change from liquid to vapor

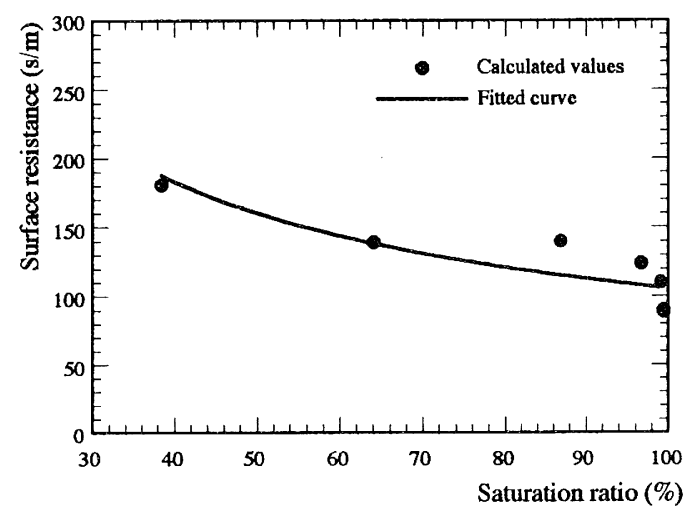

Figure 15. Effect of the saturation ratio at the top of the fine sand layer on the soil surface resistance.

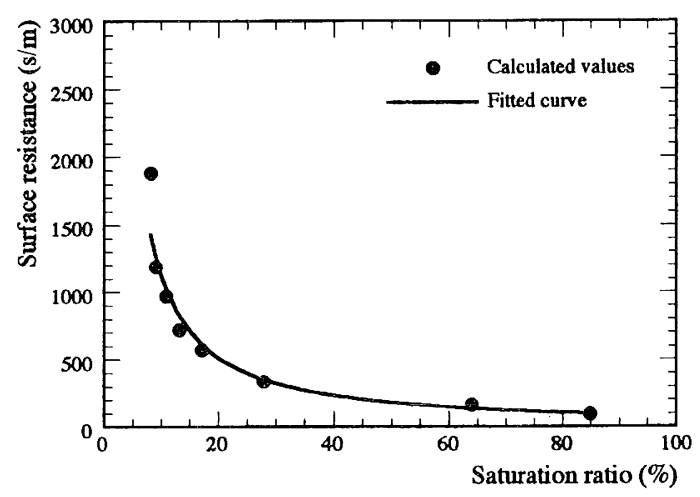

Figure 16. Effect of the saturation ratio at the top of the coarse sand layer on the soil surface resistance. does not occur at the surface itself but, consequently at some depth below the surface. This movement of the evaporative front and its effect, may be more active in the case of fine sand than that in the case of coarse sand because the volume of the soil pores is smaller in the case of fine sand.

\section{Conclusions}

Based on the Watanabe's new technique for measuring evaporation, a simple method has been developed to calculate both total resistance and aerodynamic resistance to vapor diffusion under bare soil conditions. The steady evaporation from fine sand is much larger than that from coarse sand exposed to the same atmospheric conditions and at the same depth of the ground water table. Both the steady evaporation and the surface resistance are much influenced by the moisture conditions at the very thin top layer. As the ground water table depth increases the steady evaporation from both coarse and fine sand decreases. The estimated hydraulic properties from back analysis were checked and resulted in a good accuracy to analyze the moisture movement in the unsaturated zone. The vertical saturation ratio distribution in sand soil with a shallow ground water table is slightly affected by small values of evaporation. The steady evaporation from sand soil with the presence of a shallow ground water table reaches to the steady-state in a short time (less than 3.5 hours). The surface resistance of the coarse sand is larger than that of the fine sand under the similar conditions. The surface resistance for the two types of sand (coarse and fine) was modeled quite well as a power function of soil saturation ratio in the top layer of the bare soil. A proposed iterative technique was used to calculate the surface, momentum and sensible heat roughness lengths. The bare sand surface was found to be hydrodynamically rough. For the bare sand soil both the aerodynamic resistance and the roughness lengths are independent of the soil sur- 
face moisture condition.

\section{Acknowledgment}

The authors would like to express their great gratitude and thanks to reviewers of editing committee, J. Ground water hydrology, for their valuable time spent on reviewing the paper, for their corrections of inconsistencies, professional suggestions and comments. Also, the authors are indebted to professor Momii for his comments and helpful reviews of this manuscript.

\section{References}

Abozeid A., K. Watanabe, M. Ashour, A. Nashaat and M. Ali (1996): In situ determination of the hydraulic properties of unsaturated soil. Proc. of the 51th National Conference of Japan Society of Civil Eng., Nagoya, Japan.

Brutsaert H. (1982): Evaporation into the atmosphere. Kluwer Academic Publisher.

Camillo P. J. and R. J. Gurney (1986): A resistance parameter for bare -soil evaporation models. Soil Sci., 141 (2), 95-105.

De Vries D. A. (1958): Simultaneous transfer of heat and moisture in porous media. Trans. Am. Geophys. Un., 39, 909-916.

Farrell D. A., E.L. greacen and C. G. Gurr (1966) : Vapor transfer in soil due to air turbulence. Soil Sci., 102 (5), 305-313.

Fukuda H. (1955): Air and vapor movement in soil due to wind gustiness. Soil Sci., 79, 249-256.

Ishihara Y., E. Shimojima and H. Harada (1992): Water vapor transfer beneath bare soil where evaporation is influenced by a turbulent surface wind. J. Hydrol., 131, 63-104.

Kalma J. D. and D. L. B. Jupp (1990) : Estimating evaporation from pasture using infrared thermometry: evaluation of a one-layer resistance model. Agric. For. Meteorol., 51, 223-246.

Kondo J., N. Saigusa and T. Sato (1990): A parameterization of evaporation from bare soil surfaces. J. Appl. Meteorol., 29, 385-389.
Kurokawa U., K. Watanabe, A. K. Abdel-Lah and T. Yamamoto (1995): The accuracy of the new equipment for measuring evaporation and characteristics of the evapotranspiration from plants under different conditions. J. Japan Soc. Eng. Geol., 34 (4), 27-33.

Lettau H. (1969): Note on aerodynamic roughness-parameter estimation on the basis of roughness element description. J. Appl. Meteorol., 8, 828-832.

Mahfouf J. F. and J. Noilhan (1991): Comparative study of various formulations of evaporation from bare soil using in situ data. J. Clim. Appl. Meteorol., 30 (9), $1354-1365$.

Paeschke W. (1937): Experimentelle untersuchungen zum rauhigkeits-und stabilitatsproblem in der bodennahen luftschicht. Beiträge $z$. Phys. d. freien Atmos., 24, 163-189. Quoted from Brutsaert, 1982.

Philip J. R. (1957) : Evaporation, and moisture and heat fields in the soil. J. Meteorol., 14, 354-366.

Schmugge T. J., P. E. O'Neill and J. R. Wang (1986): Passive microwave soil moisture research. IEEE Trans. Geosci. Remote sens., GE-24 (1), 12-27.

Scotter D. R. and P. A. C. Raats (1969): Dispersion of water vapor in soil due to air turbulence. Soil Sci., 108 (3), 170-176.

Shu Fen Sun (1982): Moisture and heat transport in a soil layer forced by atmospheric conditions. $M$. Sc. thesis, Univ. of Connecticut.

Tom A. S. (1975): Momentum, mass and heat exchange of plant communities. In: J. L. Monteith (Editor), Vegetation and the atmosphere. Vol. 1. Academic Press, Londen, Chapter 3, 57-109.

van Bavel C. H. M. and D. I. Hillel (1976): Calculating potential and actual evaporation from a bare soil surface by simulation of concurrent flow of water and heat. Agric. Meteorol., 17, 453-476.

van de Griend A. A. and J. H. van Boxel (1989): Water and surface energy balance model with a multilayer canopy representation for remote sensing purposes. Water Resour. Res., 25 (5), 949-971.

van de Griend A. A. and O. Manfred (1994): Bare soil surface resistance to evaporation by vapor diffusion under semiarid conditions. Water Res., 30 (2) , $181-188$ 
van-Genuchten M. Th. (1980): A closed form equation for predicating the hydraulic conductivity of unsaturated soils. Soil Sci. Soc. Am. J., 40, 892-898.

Vogt R. and L. Jaeger (1990): Evaporation from a pine forest using the aerodynamic method and Bowen ratio method. Agric. For. Meteorol., 50, 39-54.

Watanabe K., T. Sakai, Y. Hoshino and S. Hamada (1995): In-situ and laboratory tests for estimating the hydraulic properties of unsaturated rock. Proc. Inter.
Conger. on rock Mech. Japan.

Watanabe K. and Y. Tsutsui (1994): A new equipment used for measuring evaporation in a field. Proc. 7th Congr., IAEG, 309-313.

Wooding R. A., E. F. Bradley and J. K. Marshall (1973): Drag due to regular arrays of roughness elements of varying geometry. Boundary-Layer Meteorol., 5, 285-308.

(Received: 1996. 9. 25, Accepted: 1997. 3. 10) 